\title{
FORECASTING OF SPORTS FIELDS CONSTRUCTION COSTS AIDED BY ENSEMBLES OF NEURAL NETWORKS
}

\author{
Michał JUSZCZYK $\mathbb{B}^{*}$, Krzysztof ZIMA (), Wojciech LELEK \\ Faculty of Civil Engineering, Cracow University of Technology, Kraków, Poland
}

Received 13 February 2019; accepted 18 April 2019

\begin{abstract}
The paper presents an original approach to construction cost analysis and development of predictive models based on ensembles of artificial neural networks. The research was focused on the application of two alternative approaches of ensemble averaging that allow for combining a number of multilayer perceptron neural networks and developing effective models for cost predictions. The models have been developed for the purpose of forecasting construction costs of sports fields as a specific type of construction objects. The research included simulation and selection of numerous neural networks that became the members of the ensembles. The ensembles included either the networks of different types in terms of their structure and activation functions or the networks of the same type. The research also included practical implementation of the developed models for cost analysis based on a sports field BIM model. This case study examined and confirmed all of the four models' predictive capabilities and superiority over models based on single networks for the particular problem. Verification including testing and the case study enabled selection of the best ensemble-based model that combined ten networks of different types. The proposed approach is prospective for fast cost analyses and conceptual estimates in construction projects.
\end{abstract}

Keywords: construction cost management, conceptual estimates, neural networks, ensembles, artificial intelligence, building information modelling, sport fields.

\section{Introduction}

Completion of a construction project within a budget or cost limit is one of the essential objectives for a project's success. Consequently, cost estimating is one of the key processes in the construction project. Fundamental assumptions about the cost estimating, seen as a process, are that it follows the design process and the accuracy of the estimate depends on the information available at a certain stage of design development. Therefore the methods applied for cost estimating purposes applicable at successive stages of a construction project should be suited to the use of available information. Growing expectations on shortening the time of cost estimates delivery result in the exploitation of mathematical tools that aid fast cost estimates of either whole construction objects or certain scopes of construction works. On the other hand, both underestimation and overestimation are unwanted phenomena, so the estimates accuracy should meet the requirements of a specific stage of a project. Furthermore, the construction industry is witnessing the development of building information modelling - a technology that aids processing in- formation and decision-making in the course of the construction project. Cost analyses are among the processes that particularly benefit from the employment of building information modelling in construction projects.

This paper presents the results of studies on fast cost estimating methods based on the ensembles of artificial neural networks for the purposes of conceptual estimates of sports fields as specific construction objects. The main difference in the approach presented herein and the traditional application of neural networks in a similar class of problems lies in the development of a model that consists of a number of networks instead of a model based on one network. Combining several networks and forming so-called ensemble (or a committee) allows for the use of certain capabilities and advantages of such a model. The main focus of the presented research lies in analyses, neural simulations and calculations that have led to the development of four ensemble-based predictive models. The analyses are followed by a case study that shows the practical application which combines the use of the four

*Corresponding author. E-mail: mjuszczyk@L3.pk.edu.pl 
developed models and building an information model of a sports field. The research presented in this paper is part of a broad project which aims to develop cost estimation tools for the construction industry. Some previous works on the subject have dealt with the use of self-organising feature maps for clustering sports fields as specific construction objects (Juszczyk \& Zima, 2018), estimation of construction works costs for sports fields supported by single neural networks (Juszczyk, Leśniak, \& Zima, 2018), or the use of a case-based reasoning approach for construction costs estimates (Zima, 2015; Leśniak \& Zima, 2018). The paper content includes: a synthetic state-of-the-art review, main assumptions for the problem being solved along with concise presentation of the theoretical background for the mathematical tools applied, a presentation of the research results and a short case study.

\section{State-of-the-art and literature review}

Artificial neural networks (ANNs) belong to a family of artificial intelligence tools inspired by neurobiological patterns of learning and storing knowledge, which can be applied to solve a variety of classification or regression problems. The theory of neural networks is presented in many works (e.g., Bishop, 1995; Haykin, 1999; Osowski, 1997; Tadeusiewicz, 1993). Neural networks have the potential of processing data in order to find the hidden patterns. Data processing in order to gather knowledge is called the training and is implemented by specific algorithms. After being trained, the networks are supposed to be able to make predictions for the new data which was not used during the training. The generalisation of knowledge is among the most important capabilities of artificial neural networks, which makes the tool applicable for many engineering problems. Some examples of works worth mentioning include: assessing the productivity of earthmoving machinery (Schabowicz \& Hoła, 2007), the selection of construction project managers (Rashidi, Jazebi, \& Brilakis, 2011), estimation of formwork labour (Dikmen \& Sonmez, 2011), solving geodesy tasks (Mrówczyńska, 2011), dynamic assessment of construction project success (Cheng, Tsai, \& Sudjono, 2012), and modelling the dependencies between town development policy and increasing energy effectiveness (Skiba, Mrówczyńska, \& Bazan-Krzywoszańska, 2016).

Apart from the aforementioned applications for various engineering problems, neural networks are also reported to be implemented for cost-related problems in the construction industry. Liu and Ling (2005) developed fuzzy neural network model that supposedly assists a contractor in the estimation and choice of a markup. The multilayer perceptron and general regression neural networks were investigated by Petroutsatou, Georgopoulos, Lambropoulos, and Pantouvakis (2012) in light of their applicability for early estimation of road tunnels costs. Yip, Fan and Chiang (2014) reported the results of general regression neural networks application for prediction of the maintenance cost of construction equipment. The applica- tion of multilayer perceptron neural networks for building construction cost estimation in the early design phase can be found in the work of El-Sawalhi and Shehatto (2014). Research by Naik and Kumar (2015) deals with optimisation of both the cost and duration of a construction project by employing neural networks. A hybrid method, based on a combination of multivariate regression and multilayer perceptron neural networks, applied for estimation of earthmoving, loading and unloading equipment capital cost, is presented by Yazdani-Chamzini, Zavadskas, Antucheviciene, and Bausys (2017). Leśniak and Juszczyk (2018) presented research on the development of multilayer perceptron based neural networks for prediction of site overhead costs.

Ensembles of neural networks are rooted in so-called ensemble learning systems, where the members of an ensemble i.e. single trained neural networks provide predictions which are then combined, with the expectation of error reduction when compared to single neural networks. Fundamentals can be found in the earlier cited works that comprehensively present the matters of neural networks (Bishop, 1995; Haykin, 1999), as well as in works dedicated to ensembles (Sharkey, 1999). Employing ensembles of neural networks in classification and regression models, instead of single neural networks acting in isolation, is expected to result in improved performance and accuracy (Hashem \& Schmeiser, 1995).

Engineering applications of ensembles of neural networks cover such problems as: prediction of heavy construction equipment, namely tunnel boring machine, performance (Z. Zhao, Gong, Zhang, \& J. Zhao, 2007), structural damage identification (Hakim, Razak, \& Ravanfar, 2016), prediction of heating energy consumption (R. Jovanović, R. Ž. Jovanović, \& Sretenović, 2017), and visual identification of village buildings (Guo et al., 2017). Although the models based on ensembles of neural networks offer certain capabilities and advantages, they are seldom reported to be investigated in the field of construction cost analysis.

Development and evolution of building information modelling (BIM) is influencing the construction industry and changing the picture of sharing and exchange information among the participants of construction projects. The fundamentals and essentials of BIM can be found in the following works that present: a guide and thorough review of BIM (Eastman, Teicholz, Sacks, \& Liston, 2011), a discussion of potential benefits as well as challenges and risks resulting from BIM adoption in construction industry (Azhar, 2011), the methodology and BIM tools dedicated to construction management (Hardin \& McCool, 2015), and a review of information modelling process (Kalibatas, Kalibatienė, \& Kapliński, 2018).

BIM and its applications are currently discussed in different aspects and a wide spectrum of topics related to construction management, for example: assessing buildings redevelopment possibilities (Pavlovskis, Antucheviciene, \& Migilinskas, 2017), an ecologically oriented BIM-based design and refurbishment management model 
(Ustinovichius et al., 2018), opportunities and risks for construction project stakeholders resulting from BIM implementation (Grzyl, Miszewska-Urbańska, \& Apollo, 2017), promotion of sustainable solutions through employment of BIM from the point of view of design companies (Reizgevičius, Ustinovičius, Cibulskienè, Kutut, \& Nazarko, 2018).

Besides the above-mentioned BIM related issues, connotations of BIM and cost analyses are of a special interest for the problem presented in this paper. Bryde, Broquetas, and Volm (2013) mention, among others, the benefits of BIM implementation for cost management in construction projects - the positive results are considered to manifest in either cost reduction or better cost control. A study by Cheung, Rihan, Tah, Duce, and Kurul (2012) presents the use of BIM models and a multi-attributebased tool developed to evaluate various aspects of building design and, especially, to support cost analyses at the early stage of design. Forgues, Iordanova, Valdivesio, and Staub-French (2012) investigated and discussed the influence of adoption of BIM-based cost estimating software in the construction company on the process of cost estimation in terms of practices and workflows. The combined use of BIM and geospatial information system (GIS) has been explored in the context of roadworks cost estimation by Park, Kang, Lee, and Seo (2014). Zima (2017) discussed the influence of the detail level of information stored in a BIM model on the bill of quantities and cost estimates accuracy. Juszczyk (2017a) presented research on the implementation of neural networks for the purposes of BIMbased cost analyses on a macro level.

\section{General assumptions for the problem and synthesis of methodology theoretical background}

Development of a predictive model, which aims at the forecasting of the total construction costs of sports fields, as specific construction objects, comes down to solving the regression problem. The model is expected to explain the dependence between the total construction and a set of cost predictors (it is noteworthy that the individual and unique character of construction objects makes studies on the tools that aid fast cost modelling for different types of facilities encounter's distinct problems; each problem requires identification and selection of variables that play the role of cost predictors for a certain type of facility). In the course of earlier research (Juszczyk et al., 2018; Juszczyk \& Zima, 2018) the variables that are finally selected for neural modelling were investigated and examined. It was decided that the total cost of construction works that are necessary to build a sport field will constitute the dependent variable, hereinafter referred to as $y$. The independent variables, hereinafter referred to as $x_{j}$, include cost predictors which correspond to information available at the conceptual stage of design of a sports field and describe the features of such construction objects. The final set of independent variables selected to be used for the purposes of training neural networks includes 7 variables. The analysis and selection process of these variables, as well as the data collection, is presented and explained in a previous work by Juszczyk et al. (2018). Table 1 presents the dependent variable as well as the independent variables in terms of their types and values.

Table 1. Variables selected for the purpose of neural modelling

\begin{tabular}{|c|c|c|c|}
\hline Description of the variable & Variables' types & Variables' values & Symbol \\
\hline \multicolumn{4}{|l|}{ Dependent variable: } \\
\hline Total cost of construction works & Quantitative - cost given in thousands of PLN & Numerical & $y$ \\
\hline \multicolumn{4}{|l|}{ Independent variables: } \\
\hline Playing area of the sports field & Quantitative - surface area measured in $\mathrm{m}^{2}$ & Numerical & $x_{1}$ \\
\hline Type of playing field surface & Categorical - natural grass or artificial & $\begin{array}{l}\text { Pseudo fuzzy scaled: } 0.1 \\
\text { or } 0.9\end{array}$ & $x_{2}$ \\
\hline $\begin{array}{l}\text { Quality standard of the playing } \\
\text { field's surface }\end{array}$ & $\begin{array}{l}\text { Categorical - quality standard assessed according to } \\
\text { the available information in the tender documentation }\end{array}$ & $\begin{array}{l}\text { Pseudo fuzzy scaled into the } \\
\text { range: } 0.1-0.9 \\
\text { (step of the scale }=0.1 \text { ) }\end{array}$ & $x_{3}$ \\
\hline Ball stop net's surface & Quantitative - surface area measured in $\mathrm{m}^{2}$ & Numerical & $x_{4}$ \\
\hline $\begin{array}{l}\text { Arranged area for } \\
\text { communication }\end{array}$ & Quantitative - surface area measured in $\mathrm{m}^{2}$ & Numerical & $x_{5}$ \\
\hline Fencing length & Quantitative - length measured in $\mathrm{m}$ & Numerical & $x_{6}$ \\
\hline Arranged green area & Quantitative - surface area measured in $\mathrm{m}^{2}$ & Numerical & $x_{7}$ \\
\hline
\end{tabular}

Note: Data presented in the above table was synthesised on the basis of previous work (Juszczyk et al., 2018). Initially, also the location of the facility and number of the sports functions were taken into account as potential independent variables of the model, however the correlation between the two variables and dependent variable proved too weak for details compared with Juszczyk et al. (2018). 
The data, namely values of $y$ and corresponding $x_{j}$ variables as presented in the Table 1, were collected for projects completed in previous years all over Poland. The overall number of collected data patterns equalled 129. The analysis of outliers resulted in rejection of the cases for which the total construction cost was unusually high or unusually low. After the elimination of outliers, 115 data patterns remained and constituted the basis for the model development. Prior to the model development, the values of $y$, that is the total costs of construction works, were updated for the year 2018 according to the index of changes in prices of construction works costs in Poland.

The solution of the problem comes down fundamentally to regression analysis as in the Eqns (1) and (2):

$$
\begin{aligned}
& y=h\left(x_{j}\right)+\varepsilon, \\
& \hat{y}=h\left(x_{j}\right),
\end{aligned}
$$

where $y$ and $x_{j}$ stand for the variables presented in Table $1, h$ denotes regression function and $\varepsilon$ corresponds to prediction error. The use of the approach that relies on implementation of mapping $x_{j} \rightarrow y$ implicitly by neural networks can be justified by certain features of such tools synthesised after (Bishop, 1995; Haykin, 1999; Tadeusiewicz, 1993; Osowski, 1997; Juszczyk, 2017b), including:

- no need to assume an a priori analytical form of relationships between the model variables,

- the ability of learning and storing the learnt knowledge in synaptic weights,

- the ability of generalisation of the acquired knowledge,

- the ability to adapt to changing conditions,

- a small sensitivity to errors in the input data.

The traditional approach in the applications of neural networks is to choose one best network - which fulfils the requirements assumed for a certain problem - from a set of many trained and tested networks. Two main disadvantages with such an approach are mentioned in Bishop (1995): the effort involved in training the number of networks is wasted; furthermore, the generalisation per- formance on the validation set has a random component due to the noise of the data. Consequently, the one chosen network which has the best performance on the validation data might not be the one with the best performance on new test data. An alternative approach which overcomes these drawbacks relies on combining a set of trained networks to form an ensemble. According to Bishop (1995), the set might contain various kinds of network models or similar networks trained to different local minima.

The main assumption for an ensemble averaging approach is that approximation of the regression function is done with use of a linear combination of $K$ trained networks, here denoted as $f_{k}$, so that:

$$
y_{k}=f_{k}\left(x_{j}\right)+\varepsilon_{k},
$$

and

$$
\hat{y}_{k}=f_{k}\left(x_{j}\right),
$$

and

$\hat{y}=\alpha_{1} f_{1}\left(x_{j}\right)+\alpha_{2} f_{2}\left(x_{j}\right)+\ldots+\alpha_{k} f_{k}\left(x_{j}\right)+\ldots+\alpha_{K} f_{K}\left(x_{j}\right)$,

where $\varepsilon_{k}$ stands for the prediction error made by the $k$-th neural network, $k=1, \ldots, K$ and $\alpha_{k}$ are the weight coefficients for regression functions implemented implicitly by the $k$-th neural network. Figure 1 presents the ideograms and schematic prediction models based on neural networks - both with the use of a single network and an ensemble of networks.

As stated in Haykin (1999), the model developed on the basis of an ensemble averaging method belongs to the category of static structures where several predictors (neural networks in our case) are combined in a way that does not involve the input signal. This research presents an investigation of two alternative approaches rooted in ensemble averaging: the first relies on simple averaging, whilst the second involves optimisation of weights and weighted averaging.

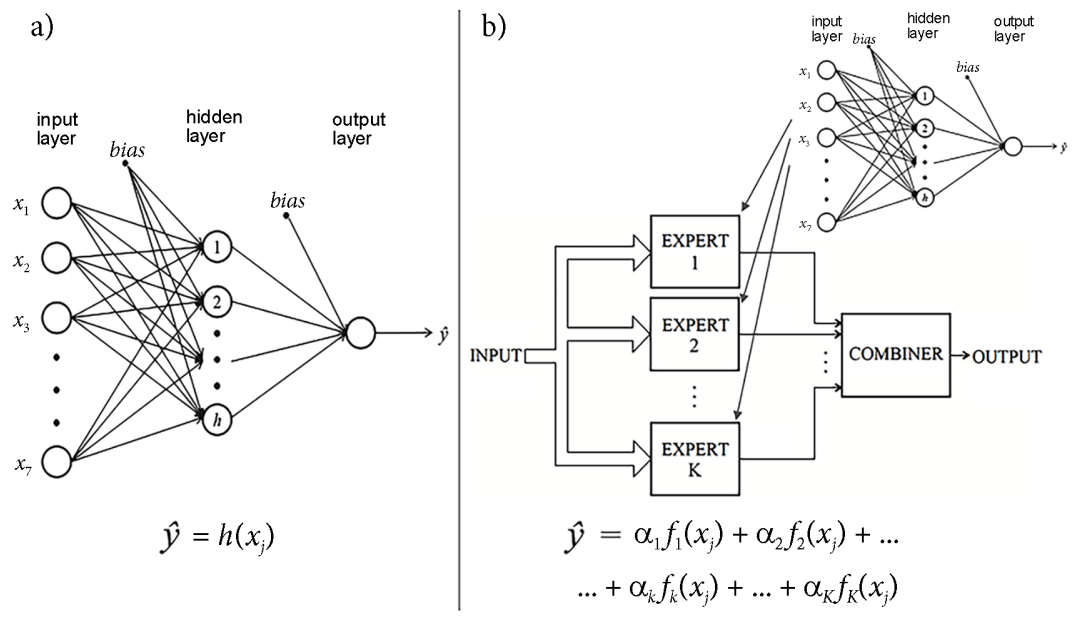

Figure 1. The difference between a traditional and ensemble-based approach in the application of neural networks: a) prediction based on a single network; b) prediction based on an ensemble including $K$ networks 
The theoretical background presented below has been synthesised after Bishop (1995). Simple form of an ensemble involves averaging of the outputs of neural networks that belong to the ensemble. On this assumption, the weight coefficients $\alpha_{k}$ are equal. For linear combination of $K$ member networks:

$$
\alpha_{k}=\frac{1}{K}
$$

after this assumption Eqn (5) can be simplified to:

$$
\hat{y}=\frac{1}{K} \sum_{k=1}^{K} f_{k}\left(x_{j}\right)=\frac{1}{K} \sum_{k=1}^{K} \hat{y}_{k} .
$$

According to Bishop (1995), taking into account the sum-of-squares error for each $k$-th member of the ensemble, assuming that the prediction errors made by the members of the ensemble have zero mean and are uncorrelated, one can conclude that the relationship of the average of the errors made by the members acting separately $E_{A V}$ and errors made by the ensemble $E_{E N S}$ can be presented as follows:

$$
E_{E N S}=\frac{1}{K} E_{A V} \text {. }
$$

In practice the errors are correlated to some extent. However, some error reduction can be obtained for the ensemble; moreover, the ensemble cannot produce an error greater than the straight average of the errors made by the members of the ensemble acting in isolation. Thus, the following inequality is true for practical implementations:

$$
E_{E N S} \leq E_{A V} \text {. }
$$

An alternative approach relay on the expectation that some networks belonging to the ensemble will make better predictions than the others. Later this approach will be addressed as generalised ensemble averaging. This involves weighted averaging and differing weights $\alpha_{k}$ such that:

$$
\sum \alpha_{k}=1,
$$

and

$$
\hat{y}=\sum_{k=1}^{K} \alpha_{k} f_{k}\left(x_{j}\right)=\sum_{k=1}^{K} \alpha_{k} \hat{y}_{k} .
$$

In order to find $\alpha_{k}$ some computation is needed. The paper includes a concise explanation of the necessary computations - the method is discussed in details in Bishop (1995).

$$
\alpha_{k}=\frac{\sum_{l=1}^{K}\left(\mathrm{C}^{-1}\right)_{k l}}{\sum_{h=1}^{K} \sum_{l=1}^{K}\left(\mathrm{C}^{-1}\right)_{h l}},
$$

where $C$ is an error correlation matrix of errors produced by the members of an ensemble. In Eqns (12) and (13) for clarity the member networks are marked by indexes $k, h$ and $l$. Elements of $C$ are computed with the use of finitesample approximation:

$$
C_{k l} \cong \frac{1}{N} \sum_{p}\left(\hat{y}_{k}^{p}-y^{p}\right)\left(\hat{y}_{l}^{p}-y^{p}\right),
$$

where $p$ denotes the sample for which predicted and expected values are given, corresponding with vector $\left(x_{j}\right) p$, and $N$ stands for cardinality of a set of samples. Since the approach is a special case of ensemble averaging, the following conclusion in the form inequality can be drawn:

$$
E_{G E N} \leq E_{E N S},
$$

where $E_{G E N}$ stands for the prediction error produced by a model built on the generalised ensemble averaging approach.

Apart from the advantages that arise from the theoretical considerations, the main motivation for an investigation of the applicability of ensembles of neural networks for forecasting construction costs of sports fields is rooted in the previous research presented by Juszczyk et al. (2018). In the aforementioned work the adopted strategy for the purpose of investigating the performance of the chosen best single network relied on training and testing processes with the use of different learning, validating and testing subsets selected from the whole set of collected data patterns, including $y$ and $x_{j}$ values (compare with Table 1 ). Although the performance was satisfactory, dependence between the performance and selection of the mentioned subsets was clearly visible. The expectation about the implementation of an ensemble, instead of a single network, into the prediction model was to objectify cost forecasts and make them less dependent on the subsets selection. The details of the strategy adopted for development models based of ensembles of neural networks are explained in the next section.

\section{Strategy of ensemble-based model development and research results}

The number of data patterns of $y$ and $x_{j}$ variables, as presented in Table 1, used in the course of model development equalled 115 . The data set was divided into two main subsets - the first subset included data used for the supervised training purposes, whilst the second was used for testing purposes. The testing subset was selected carefully so the data belonging to this subset was firstly equivalent to the data belonging to the training subset and, secondly, the variety of the sports fields (as a specific construction objects), reflected by variables values, was representative for the whole set of data used for the model development. The testing subset, later referred to as $T$, included $10 \%$ of the data patterns used in the course of the model development. The data belonging to the testing subset did not take part in the training process, as the main purpose of testing was to examine the ability of knowledge generalisation. Thus, the testing was performed with the use of data not presented to the ANNs earlier (compare, e.g., Bishop, 1995; Haykin, 1999; Tadeusiewicz, 1993). Patterns belonging to the $T$ subset were used for testing of single networks that were taken into account as candidates to be the members of the ensembles, as well as the ensembles. Testing performed in such a way allowed for assessment of candidate networks and a comparison of the ensem- 
bles performance with the use of the same subset. In other words the assessment of both the performance of ANNs acting in isolation and the performance of ensembles of ANNs was provided on the basis of the same criteria. The remaining $90 \%$ of data patterns were divided into subsets used in the learning and validating phase of training of single networks that were taken into account as candidates to be the members of ensembles. The division ratio into the learning subset (later referred to as $L$ ) and validating subset (later referred to as $V$ ) equalled $L / V=90 \% / 10 \%$. The division into $L$ and $V$ subsets was repeated 10 times, which made 10-fold data available for training purposes. One of the fundamental assumptions was to carry out the training process with the use of different learning and validating subsets, and to ensure that each of the training patterns took part in the learning process 9 fold and in the validating process 1 fold. Depending on the fold, the data belonging to the $L$ or $V$ subsets was rotated between the learning and validation processes and contributed in the training process accordingly.

It was assumed that the structures of the investigated ensembles include 10 multilayer perceptron networks (hereinafter referred to as MLP) with one hidden layer. For each of the previously mentioned folds of $L$ and $V$ subsets, 1 network was chosen. Two variants of ensembles structures were considered in the course of the research:

- ensemble that consisted of different networks that varied in the number of hidden neurons and activation functions,

- ensemble that consisted of neural networks of the same number of hidden neurons and the same activation functions - the structure of network and its characteristics resulted from the previous research (Juszczyk et al., 2018).

For both variants above, the two alternative ensemble approaches explained in the previous section were applied. These assumptions resulted in four ensemble-based models that were developed - details regarding these four models can be found in Table 2 .

The number of hidden units in the case of candidate networks for ENS 1 and GEN 2 (in Table 2, denoted as $H$ ) varied between 2 and 6 . Before the phase of training and testing all data values for $y$ and $x_{j}$ variables were scaled to the ranges appropriate for certain types of activation functions assumed for neural networks. The scaling process was provided automatically by the software used for the purposes of ANNs simulations. All the candidate networks varied also in the initial conditions of the learning process, namely initial weights of the neurons. The training of all the neural networks were made with use of STATISTICA software suite with the use of the Broyden-Fletcher-Goldfarb-Shanno (BFGS) algorithm.

In the case of the ENS 1 and GEN 2 ensembles, 100 candidate networks were trained for each fold of data. Performance analysis of the candidate networks and selection of the ensemble members included two steps. Due to the variety of networks, the aim of the first step was to choose a group of 20 networks (out of 100) with good and comparable performance. This choice depended on:

- the highest values of Pearson's coefficient $(R)$ that reflected the correlation between the predicted and real life values of the dependent variable,

- the lowest error measures, root mean square errors (RMSE) and mean absolute percentage errors (MAPE).

Equations (15)-(17) present the above-mentioned measures used for the assessment of the candidate networks and for the selection of members of the ensembles:

$$
\begin{aligned}
& R=\frac{\operatorname{cov}(y, \hat{y})}{\sigma_{y} \sigma_{\hat{y}}}, \\
& R M S E=\sqrt{\frac{1}{c} \sum_{p}\left(y^{p}-\hat{y}^{p}\right)^{2}}, \\
& M A P E=\frac{100 \%}{c} \sum_{p}\left|\frac{y^{p}-\hat{y}^{p}}{y^{p}}\right|,
\end{aligned}
$$

where $\operatorname{cov}(y, \hat{y})$ stands for covariance between $\mathrm{y}$ and $\hat{\mathrm{y}}, \sigma_{y}-$ standard deviation for $\mathrm{y}, \sigma_{\hat{y}}$ - standard deviation for $\hat{y}, c$ for cardinality of subsets used for learning $-L$, validation $-V$, learning and validation together $-L \& V$, testing $-T$, and $p$ stands for the index of pattern belonging to the certain subset of data. Values of RMSE and MAPE presented later in the paper were computed for the unscaled values of $y$ and $\hat{y}$.

In the second step, to finally select one member network for each fold (out of 20), each of the candidate networks underwent careful residuals analysis in terms of errors distribution and dispersion. The final selection of the member networks depended on the best performance for the testing subset.

For the ensembles ENS 3 and GEN 4, the selection pro-

\begin{tabular}{|c|c|c|c|c|}
\hline Symbol & Approach & $\begin{array}{c}\text { MLP } \\
\text { structures }\end{array}$ & $\begin{array}{l}\text { Activation function } \\
\text { hidden layer }\end{array}$ & $\begin{array}{l}\text { Activation function } \\
\text { output layer }\end{array}$ \\
\hline ENS 1 & Simple ensemble averaging & \multirow{2}{*}{$7-H-1$} & \multirow{2}{*}{$\begin{array}{l}\text { Various functions including: } \\
\text { sigmoid, hyperbolic tangent, } \\
\text { exponential, linear }\end{array}$} & \multirow{2}{*}{$\begin{array}{l}\text { Various functions including: } \\
\text { sigmoid, hyperbolic tangent, } \\
\text { exponential, linear }\end{array}$} \\
\hline GEN 2 & Generalized ensemble averaging & & & \\
\hline ENS 3 & Simple ensemble averaging & \multirow{2}{*}{$7-5-1$} & \multirow{2}{*}{ sigmoid } & \multirow{2}{*}{ linear } \\
\hline GEN 4 & Generalized ensemble averaging & & & \\
\hline
\end{tabular}
cess of the member networks was simpler due to the fact

Table 2. Investigated variants of ensembles 


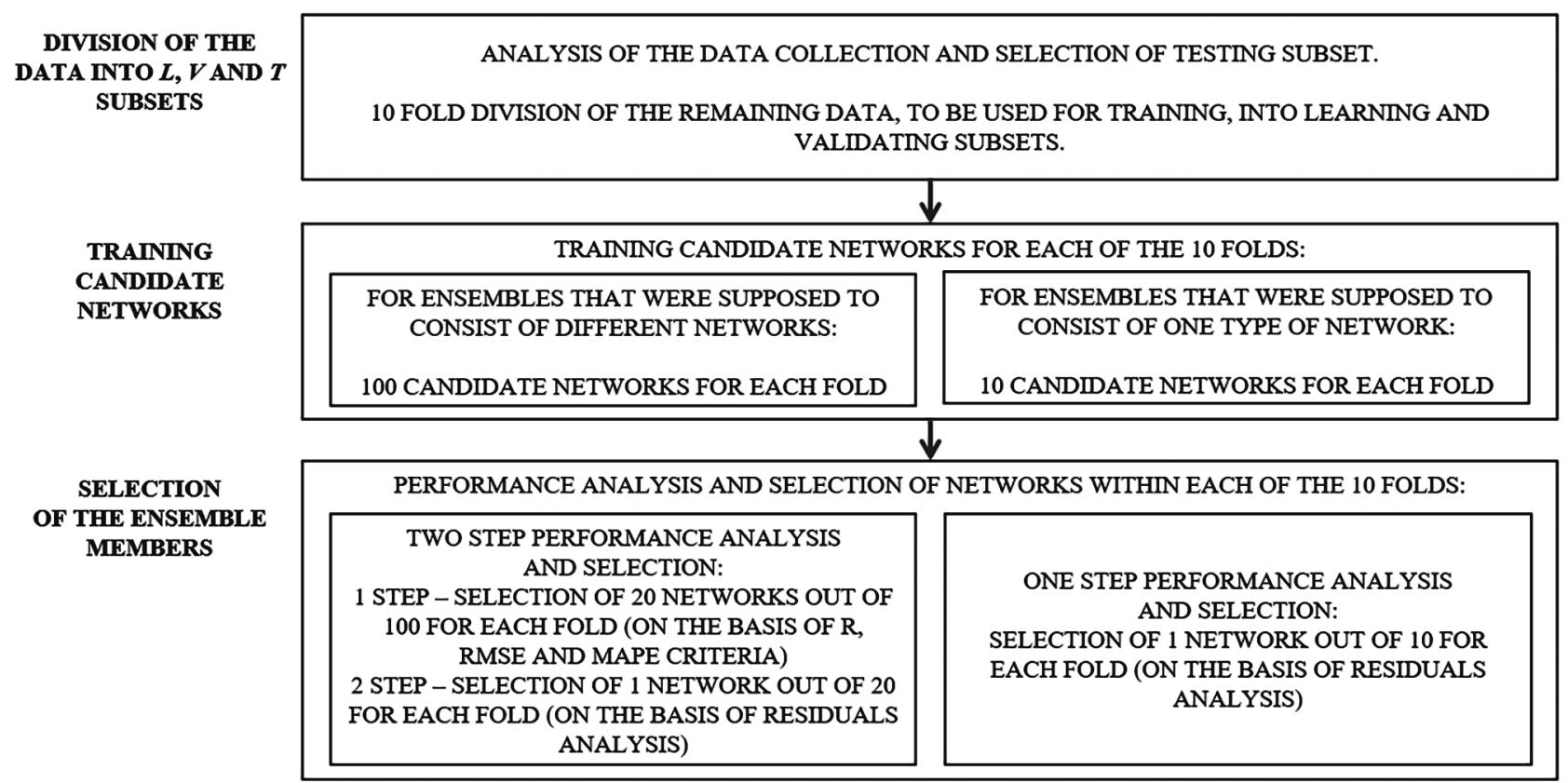

Figure 2. Training of the candidate networks and selection of the members of the ensembles ideogram

that the structure of the candidate networks was uniform. 10 candidate networks were trained for each fold of data. The final selection of one member network for each fold (out of 10) relied on residuals analysis and best performance for the testing subset just as in case of the candidate networks for ENS 1 and GEN 2.

Figure 2 presents synthetically an ideogram of the data handling, training candidate networks and selection of the networks to be the members of the ensembles.

The selection process and establishing the four ensembles composition, was followed by computations that employed Eqns (6)-(7) in the case of ENS 1 and ENS 3, and Eqns (11)-(13) in the case of GEN 2 and GEN 4. Assessment of the ensembles performance included analysis of prediction errors, especially those obtained for the testing subset.

\section{Results and discussion}

Table 3 below presents the neural networks selected to be the members of the ENS 1 and GEN 2 ensembles. The symbols of the networks, namely ANN, are followed by numbers referring to the successive ten folds of learning and validating data, as explained previously. Characteristics presented in the Table include the structure of network (especially in terms of hidden units), employed activation functions and number of epochs needed to train a particular network.

Table 4 presents the measures of errors, namely RMSE and MAPE obtained for neural networks, members of the ENS 1 and GEN 2 ensembles, acting in isolation. The RMSE and MAPE values are given for the data that took part in the training process, that is learning and validating subsets together $-L \& V$, and for the data used for the testing purposes $-T$ subset.

Table 3. Networks selected to be the members of ensembles ENS 1 and GEN 2

\begin{tabular}{|c|c|c|c|c|}
\hline Symbol & MLP structure & Activation function hidden layer & Activation function output layer & Number of training epochs \\
\hline ANN 1 & $7-5-1$ & Sigmoid & Linear & 76 \\
\hline ANN 2 & $7-4-1$ & Hyperbolic tangent & Sigmoid & 36 \\
\hline ANN 3 & $7-6-1$ & Hyperbolic tangent & Sigmoid & 31 \\
\hline ANN 4 & $7-5-1$ & Sigmoid & Linear & 37 \\
\hline ANN 5 & $7-6-1$ & Hyperbolic tangent & Exponential & 38 \\
\hline ANN 6 & $7-5-1$ & Sigmoid & Linear & 35 \\
\hline ANN 7 & $7-3-1$ & Hyperbolic tangent & Linear & 57 \\
\hline ANN 8 & $7-2-1$ & Sigmoid & Hyperbolic tangent & 59 \\
\hline ANN 9 & $7-2-1$ & Sigmoid & Linear & 83 \\
\hline ANN 10 & $7-2-1$ & Hyperbolic tangent & Hyperbolic tangent & \\
\hline
\end{tabular}


Table 4. RMSE and MAPE errors obtained for the networks that were selected as members of the ENS 1 and GEN 2 ensembles acting in isolation

\begin{tabular}{|c|c|c|c|c|}
\hline Symbol & $R M S E_{L \& V}$ & $R M S E_{T}$ & $M A P E_{L \& V}$ & $M A P E_{T}$ \\
\hline ANN 1 & 48.98 & 51.37 & $10.73 \%$ & $5.94 \%$ \\
\hline ANN 2 & 60.59 & 46.89 & $10.85 \%$ & $6.09 \%$ \\
\hline ANN 3 & 53.26 & 56.15 & $12.66 \%$ & $4.37 \%$ \\
\hline ANN 4 & 60.82 & 51.01 & $7.88 \%$ & $4.76 \%$ \\
\hline ANN 5 & 54.32 & 48.04 & $12.83 \%$ & $5.04 \%$ \\
\hline ANN 6 & 61.63 & 61.45 & $9.71 \%$ & $6.50 \%$ \\
\hline ANN 7 & 49.76 & 59.88 & $11.94 \%$ & $4.07 \%$ \\
\hline ANN 8 & 55.70 & 57.95 & $9.48 \%$ & $6.75 \%$ \\
\hline ANN 9 & 48.31 & 58.23 & $11.22 \%$ & $5.45 \%$ \\
\hline ANN 10 & 68.16 & 58.98 & $13.67 \%$ & $7.20 \%$ \\
\hline
\end{tabular}

The average values of $R M S E_{L \& V}$ and $R M S E_{T}$ presented in Table 4 equalled 56.15 and 55.00 respectively. One can see that the spread of RMSE is small, and the values are convergent. In terms of MAPE values there are some differences between the member networks which reflect the differences in performance and dependence of composition of $L$ and $V$ subsets in the 10 folds.

In the case of ensembles ENS 3 and GEN 4 all the candidate networks had the same characteristics (as presented in Table 2), thus the members of these ensembles are named $\mathrm{MLP}_{s-1,7-5-1}$. The number which follows this symbol refers to the successive ten folds of learning and validating data, as explained earlier. Table 5 presents the measures of errors, namely RMSE and MAPE obtained for neural networks, members of ensembles ENS 3 and GEN 4, acting in isolation. Values are given in the same manner as in the case of Table 4.

The average values of $R M S E_{L \& V}$ and $R M S E_{T}$ presented in Table 5 equalled 48.00 and 39.89 respectively. When

Table 5. RMSE and MAPE errors obtained for the networks that were selected as members of the ensembles ENS 3 and GEN 4 acting in isolation

\begin{tabular}{|c|c|c|c|c|}
\hline Symbol & $R M S E_{L \& V}$ & $R_{M S E_{T}}$ & $M A P E_{L \& V}$ & $M A P E_{T}$ \\
\hline $\operatorname{MLP}_{s-1,7-5-1} 1$ & 53.45 & 49.67 & $14.88 \%$ & $6.77 \%$ \\
\hline $\mathrm{MLP}_{s-1,7-5-1} 2$ & 33.64 & 31.40 & $8.93 \%$ & $4.93 \%$ \\
\hline $\operatorname{MLP}_{s-1,7-5-1} 3$ & 61.12 & 60.87 & $15.18 \%$ & $7.00 \%$ \\
\hline $\operatorname{MLP}_{s-1,7-5-1} 4$ & 48.72 & 30.85 & $12.83 \%$ & $4.68 \%$ \\
\hline $\operatorname{MLP}_{s-1,7-5-1} 5$ & 66.87 & 71.52 & $19.01 \%$ & $10.00 \%$ \\
\hline $\operatorname{MLP}_{s-1,7-5-1} 6$ & 38.64 & 25.77 & $9.86 \%$ & $3.90 \%$ \\
\hline $\operatorname{MLP}_{s-1,7-5-1} 7$ & 61.40 & 67.30 & $16.01 \%$ & $6.32 \%$ \\
\hline $\operatorname{MLP}_{s-1,7-5-1} 8$ & 39.64 & 11.85 & $12.80 \%$ & $1.91 \%$ \\
\hline $\mathrm{MLP}_{s-1,7-5-1} 9$ & 42.43 & 25.14 & $11.81 \%$ & $4.07 \%$ \\
\hline $\mathrm{MLP}_{s-1,7-5-1} 10$ & 34.09 & 24.55 & $8.68 \%$ & $3.67 \%$ \\
\hline
\end{tabular}

compared to the RMSE values presented in Table 4, the average values are smaller, however the spread of RMSE values computed for $\mathrm{MLP}_{s-1,7-5-1}$ type networks is greater. Similarly, the MAPE values there reveal greater differences between the member networks and, consequently, in their performance. The dependence on the composition of the $L$ and $V$ subsets in the 10 folds is also deeper.

Table 6 presents the weights for each ensemble member. In the case of ENS 1 and ENS 3 the weights fulfil the assumption given in Eqn (6). For GEN 2 and GEN 4, the weights were computed according to Eqns (12)-(13). The elements of the error correlation matrix $C$ were computed according to Eqn (13). The finite sample necessary for the computations included the values of $y^{p}$ used in the course of training and $\hat{y}^{p}$ as corresponding predicted values. Next, the inverse matrix $C^{-1}$, were computed. The elements of $C^{-1}$ allowed, finally, for the computations of $\alpha_{k}$ according to Eqn (12). The computations were performed for GEN 2 and GEN 4 separately.

Table 6. Weights $\alpha_{k}$ for the members of ensembles ENS 1, GEN 2, ENS 3 and GEN 4

\begin{tabular}{|c|c|c|c|c|c|}
\hline \multirow{2}{*}{ Symbol } & \multicolumn{2}{|c|}{$\alpha_{k}$} & \multirow{2}{*}{ Symbol } & \multicolumn{2}{|c|}{$\alpha_{k}$} \\
\cline { 5 - 6 } & ENS 1 & GEN 2 & & ENS 3 & GEN 4 \\
\hline ANN 1 & 0.100 & 0.461 & $\operatorname{MLP}_{s-1,7-5-1} 1$ & 0.100 & -0.003 \\
\hline ANN 2 & 0.100 & 0.031 & $\operatorname{MLP}_{s-1,7-5-1} 2$ & 0.100 & 0.516 \\
\hline ANN 3 & 0.100 & 0.250 & $\operatorname{MLP}_{s-1,7-5-1} 3$ & 0.100 & 0.023 \\
\hline ANN 4 & 0.100 & 0.076 & $\operatorname{MLP}_{s-1,7-5-1} 4$ & 0.100 & -0.033 \\
\hline ANN 5 & 0.100 & 0.045 & $\operatorname{MLP}_{s-1,7-5-1} 5$ & 0.100 & 0.043 \\
\hline ANN 6 & 0.100 & 0.060 & $\operatorname{MLP}_{s-1,7-5-1} 6$ & 0.100 & -0.002 \\
\hline ANN 7 & 0.100 & 0.068 & $\operatorname{MLP}_{s-1,7-5-1} 7$ & 0.100 & -0.052 \\
\hline ANN 8 & 0.100 & 0.263 & $\operatorname{MLP}_{s-1,7-5-1} 8$ & 0.100 & 0.075 \\
\hline ANN 9 & 0.100 & 0.110 & $\operatorname{MLP}_{s-1,7-5-1} 9$ & 0.100 & -0.005 \\
\hline ANN 10 & 0.100 & -0.365 & $\operatorname{MLP}_{s-1,7-5-1} 10$ & 0.100 & 0.438 \\
\hline
\end{tabular}


Predictions made by the four ensemble-based models were computed with the use of Eqns (7) for ENS 1 and ENS 3, and (11) for GEN 2 and GEN 4.

For the purposes of assessment of the results, a multiple regression-based model was also developed as a benchmark with the use of classical least square method. This model is hereinafter called MREG. To make this model comparable with the models based on ensembles of ANNs, its structural parameters were estimated on the basis of the values of $y$ and $x_{j}$ variables belonging to training subset. The testing subset was used for the computations of predictions and prediction errors in the same way as in case of the models based on ensembles of ANNs. Estimations of the structural parameters of MREG model with the corresponding standard errors are presented in Eqn (18):

$$
\begin{gathered}
\hat{y}=-438.78+0.323 x_{1}+81.79 x_{2}+886.81 x_{3}+0.034 x_{4}+0.057 x_{5}+0.127 x_{6}+0.001 x_{7} \\
.(39.125) \cdot(0.017) \cdot(34.045) \cdot(52.492) \cdot(0.027) \cdot(0.285) \cdot(0.074) \cdot(0.015)
\end{gathered}
$$

Table 7 presents the measures of errors, namely RMSE and MAPE, obtained for the four developed ensembles of neural networks and the multiple regression-based model as a benchmark. The values are given for the training and testing data subsets in the same manner as in Tables 4 and 5 .

The comparison of RMSE values, as the overall measures of error, obtained for the four developed ensembles (Table 7) and RMSE average values obtained for the member networks acting in isolation (Tables 4 and 5) confirm the theoretical assumptions formulated as Eqns (9) and (14). Moreover, both in the case of RMSE and MAPE, a significant improvement in overall prediction performance is noticeable in favour of the ensembles. When compared to the benchmark model MREG, the models based on ensem-

Table 7. RMSE and MAPE values obtained for ensembles of neural networks

\begin{tabular}{|c|c|c|c|c|}
\hline Symbol & $R M S E_{L \& V}$ & $R M S E_{T}$ & $M A P E_{L \& V}$ & $M A P E_{T}$ \\
\hline ENS 1 & 44.83 & 47.26 & $9.81 \%$ & $2.73 \%$ \\
\hline GEN 2 & 39.78 & 43.30 & $9.21 \%$ & $3.02 \%$ \\
\hline ENS 3 & 40.92 & 27.79 & $10.77 \%$ & $3.69 \%$ \\
\hline GEN 4 & 31.70 & 23.57 & $8.46 \%$ & $3.91 \%$ \\
\hline MREG & 75.30 & 103.99 & $16.05 \%$ & $7.09 \%$ \\
\hline
\end{tabular}

bles of ANNs proved their superiority; RMSE and MAPE values were considerably lower in favour of the latter.

Apart from the overall error measures assessment, a more profound analysis of the performance of the four developed ensembles was carried out. The analysis included a comparison of the cost predictions and absolute percentage errors $(A P E)$ frequencies and distributions for the testing subset. In Table 8 , the data belonging to the testing subset (values of both cost predictors $x_{j}$ and real life values of sports fields construction costs $y$ ) are set together with cost forecasts $\hat{y}$ computed for ENS 1, GEN 2, ENS 3, GEN 4 and, additionally, for MREG as a benchmark.

In Figure 3, one can see scatter plots of the points that represent real life values $y$ and predicted values $\hat{y}$ obtained for the four developed ensembles and for the multiple regression-based model as a benchmark.

The points in the graph represent the results of model testing and performance verification with the use of patterns belonging to the testing subset. The pairs $\left(y^{p}, \hat{y}^{p}\right)$ for $p$ belonging to the testing subset can also be found in Table 8 . The distribution of points indicates that in general the quality of forecasts is comparable for all of the four ensembles. There are no large deviations from the line of a perfect fit in the case of any of the ensembles. Especially in the range of construction costs between 125 and 750 thou-

Table 8. Ensemble based cost prediction for the testing subset

\begin{tabular}{|c|c|c|c|c|c|c|c|c|c|c|c|c|c|}
\hline$p$ & $x_{1}$ & $x_{2}$ & $x_{3}$ & $x_{4}$ & $x_{5}$ & $x_{6}$ & $x_{7}$ & $y$ & $\hat{y}_{E N S 1}$ & $\hat{y}_{G E N 2}$ & $\hat{y}_{\text {ENS3 }}$ & $\hat{y}_{\text {GEN4 }}$ & $\hat{y}_{M R E G}$ \\
\hline 7 & 584.5 & 0.1 & 0.3 & 144.0 & 0.0 & 72.0 & 0.0 & 149.10 & 149.08 & 155.87 & 151.46 & 162.21 & 103.60 \\
\hline 21 & 880.0 & 0.9 & 0.3 & 550.0 & 88.2 & 0.0 & 800.0 & 235.00 & 235.07 & 233.93 & 216.38 & 226.71 & 209.42 \\
\hline 32 & 1080.0 & 0.1 & 0.3 & 0.0 & 0.0 & 138.0 & 0.0 & 274.00 & 278.18 & 269.80 & 271.30 & 292.18 & 266.99 \\
\hline 38 & 924.0 & 0.1 & 0.4 & 795.0 & 0.0 & 0.0 & 128.0 & 324.00 & 324.75 & 333.56 & 318.66 & 337.72 & 315.15 \\
\hline 57 & 1300.0 & 0.9 & 0.4 & 318.0 & 102.0 & 100.0 & 0.0 & 439.60 & 435.39 & 444.63 & 430.31 & 448.59 & 438.55 \\
\hline 66 & 1222.0 & 0.9 & 0.5 & 180.0 & 250.0 & 154.0 & 0.0 & 491.40 & 516.82 & 527.07 & 506.82 & 519.60 & 512.55 \\
\hline 76 & 968.0 & 0.9 & 0.9 & 835.2 & 172.0 & 0.0 & 0.0 & 562.60 & 555.94 & 571.08 & 527.15 & 547.08 & 517.74 \\
\hline 88 & 2825.9 & 0.9 & 0.3 & 100.0 & 324.1 & 210.0 & 286.0 & 772.10 & 785.60 & 760.86 & 842.62 & 737.37 & 861.74 \\
\hline 94 & 2561.7 & 0.9 & 0.4 & 653.0 & 286.7 & 37.0 & 1106.0 & 922.00 & 873.13 & 921.72 & 918.80 & 884.70 & 860.68 \\
\hline 97 & 2795.0 & 0.9 & 0.8 & 740.0 & 91.3 & 140.0 & 500.0 & 1270.70 & 1168.12 & 1183.45 & 1239.45 & 1273.02 & 1029.14 \\
\hline 100 & 3292.0 & 0.9 & 0.5 & 600.0 & 2142.0 & 0.0 & 0.0 & 1359.00 & 1346.76 & 1348.56 & 1402.68 & 1382.63 & 1282.92 \\
\hline 103 & 3292.0 & 0.9 & 0.5 & 960.0 & 1490.0 & 0.0 & 0.0 & 1478.60 & 1365.29 & 1364.04 & 1448.21 & 1438.23 & 1258.28 \\
\hline
\end{tabular}




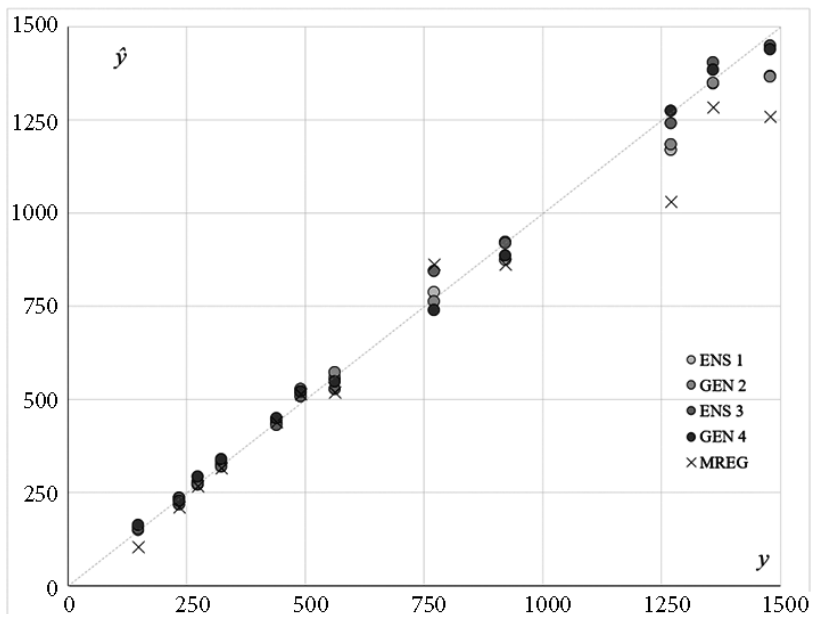

Figure 3. Scatter plots of testing results for the four developed ensemble-based models and the multiple regression-based model

sands of PLN, the predictions are coherent. In the range of construction costs between 750 and 1500 thousands of PLN, there are slight differences in the quality of the predictions - the deviations from the line of a perfect fit are more visible. One can see that in comparison to the model based on the multiple regression, the predictions offered by the ensembles are significantly better in the range of costs between 125 and 250 thousands of PLN as well as in the range between 1250 and 1500 thousands of PLN.

Frequencies and distributions of $A P E$ errors for the testing subset are depicted in Figure 4.

Values of $A P E$ were computed for the data belonging to testing subset according to the following equation:

$$
A P E^{p}=\left|\frac{y^{p}-\hat{y}^{p}}{y^{p}}\right| \cdot 100 \%,
$$

where $p$ denotes the data pattern belonging to the testing subset. $A P E^{p}$ values were accumulated for each of the four developed ensembles in the left-side closed intervals whose range equalled $2.5 \%$ - the bounds of the mentioned intervals are given in the horizontal axis of the graph in Figure 4. The last interval included $A P E^{P}>20 \%$. In this graph, one can see that $A P E^{P}$ for predictions obtained for the testing subset are smaller than $10 \%$ in the case of all of the four ensembles. The performance of all of the four ensembles is satisfying from the point of view of conceptual estimates accuracy. According to the expectations presented in the professional literature, conceptual estimates errors should fall into the range of $\pm 25 \%$. In Figure 4 one can see that for all the four models $A P E^{P}$ predictions errors fall, in the worst case, in the interval 7.5\%-10.0\%. APEP predictions errors are lower than $10 \%$ for all the samples belonging to the testing subset. The testing results for the MREG model revealed that predictions offered by the ensemble-based models are considerably better both in terms of APE errors frequencies and distributions. What is also noteworthy, the maximum value of $A P E^{p}$ obtained for the testing subset in the case of MREG model equalled $30.51 \%$.

The obtained results allow to state that the developed ensemble based models proved better performance than the networks acting in isolation. The overall measures of errors, namely RMSE and MAPE, if one compares the values presented in Tables 4, 5 and 7, confirm the superiority of ensembles for the investigated problem. The reason for this rests in the compensation of errors produced by single networks when these networks are combined to form the ensembles.

When comparing the two approaches - namely simple averaging and generalised averaging - the first one is very straightforward. To combine some trained networks and produce ensemble-based predictions one needs to take the average of outputs. The second approach requires extra effort to compute the weights, but when it is done the predictions rely on the weighted average of outputs

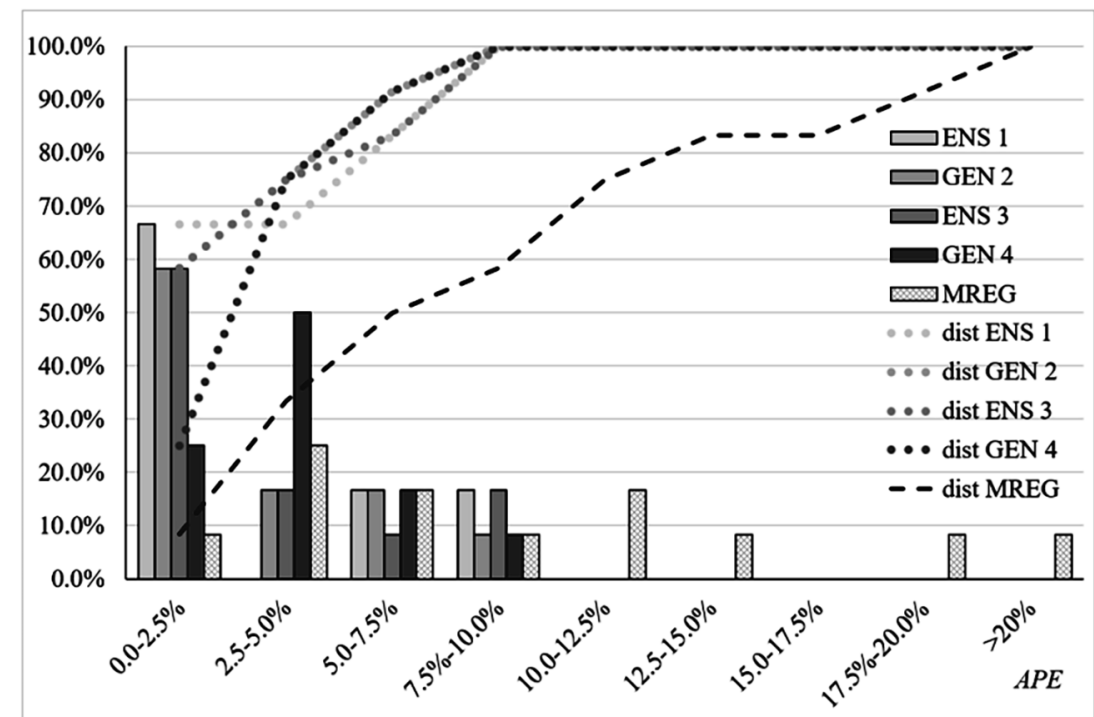

Figure 4. Frequencies and distributions of APE errors for the four developed ensemble-based models and the multiple regression based model 

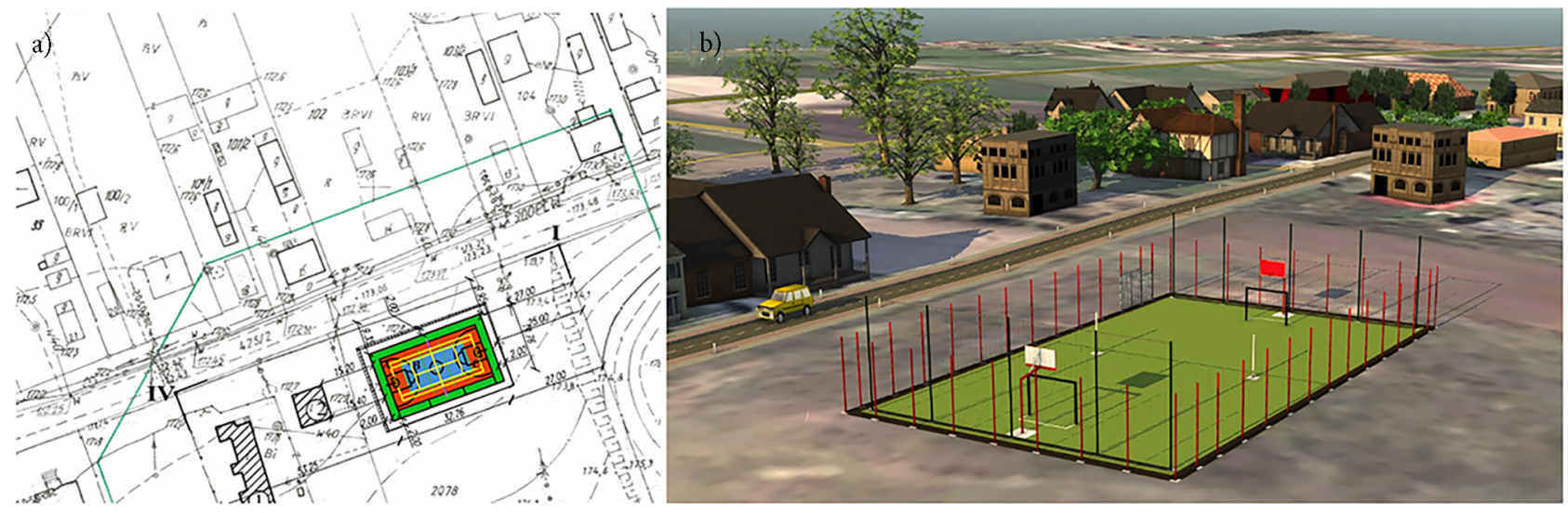

Figure 5. Location and visualisation of the sports field: a) base map and location;

b) conceptual BIM model and visualisation

of the networks that were selected to be the members of the ensemble. In the investigated problem, in the case of the ENS 1 and ENS 3 ensembles, the impact of all of the member networks on the ensembles outputs is equal. In the case of GEN 2 and GEN 4, the weights $\alpha_{k}$ presented in Table 6 reflect the impact of the certain member network on the ensemble output. In the case of GEN 2, there are four dominating networks and the rest of the weights is relatively equal - there are no networks whose impact is lower than $1.5 \%$. Otherwise the weights presented for GEN 4 reveal that there are two dominating networks - in the case of five networks the percentage impact ranges between $1.93 \%$ and $6.30 \%$, and in case of three networks the impact is lower than $0.5 \%$.

The general advantage of an ensemble-based approach - as confirmed by the presented research - is that

Table 9. Parameters of the analysed sports field

\begin{tabular}{|l|c|}
\hline \multicolumn{1}{|c|}{ Parameter description } & Value \\
\hline Number of functions & Basketball, volleyball, handball \\
\hline Types of sports & $\begin{array}{c}\text { Artificial, permeable made of } \\
\text { polyurethane }\end{array}$ \\
\hline Playing field surface type & $647.34 \mathrm{~m}^{2}$ \\
\hline Total area of facility & $32.60 \mathrm{~m}$ \\
\hline Playing field length & $19.60 \mathrm{~m}$ \\
\hline Playing field width & $638.96 \mathrm{~m}^{2}$ \\
\hline Playing field area & $216.0 \mathrm{~m}^{2}$ \\
\hline Ball stop net surface & $0 \mathrm{~m}^{2}$ \\
\hline $\begin{array}{l}\text { Arranged area for } \\
\text { communication }\end{array}$ & $105.04 \mathrm{~m}$ \\
\hline Fencing length & $0 \mathrm{~m}^{2}$ \\
\hline Arranged green area & Simple \\
\hline Ground conditions & None \\
\hline $\begin{array}{l}\text { Negative impact on the } \\
\text { environment }\end{array}$ & \\
\hline
\end{tabular}

Note: source - own study on the basis of the design documentation, publically available from Urząd Zamówień Publicznych (2019) the effort necessary for training and testing a number of neural networks is not wasted on the selection of a single network. This remark is especially significant due to the fact that nowadays it is possible to investigate numbers of networks in a relatively short time with the use of fast computers and efficient software. A limitation of the developed models, at the current stage of research, is that the cost predictions are made for the values updated for the year 2018. This is going to be addressed in further works.

\section{Case study - employing developed models for a sports field construction cost forecasts with the use of a BIM model}

Apart from the testing and discussion of its results, all of the four developed ensembles of neural networks were employed in the case study that covered the issue of construction works cost estimation for a project on a certain sports field. The case study presented in this section shows an attempt of implementation of the developed ensembles in practice for cost estimation. The analysed sports field is located in Poland in the Lublin province. Figure 5 presents the location of the analysed sports field and its closest neighbourhood.

The sports field was contracted as a subject matter of public construction works in the design-bid-build system. The description and technical details given below of the sports field have been synthesised after publically available design documentation. The facility was designed as a multifunctional sports field allowing for arranging games in three different disciplines - basketball, volleyball and handball - with the playing field $32.60 \mathrm{~m}$ long and $19.60 \mathrm{~m}$ wide. The surface of the playing field was designed as permeable, made of polyurethane - with the base layer, $7 \mathrm{~mm}$ thick, made of styrene butadiene rubber (SBR) granules bounded by polyurethane adhesive and the top layer, also $7 \mathrm{~mm}$ thick, made of coloured ethylene propylene diene monomer rubber (EPDM) granules. The contract also included $6.0 \mathrm{~m}$ high ball stop nets and $4.0 \mathrm{~m}$ high fencing. According to the design documentation, the facility has been qualified as not causing a negative impact on the en- 


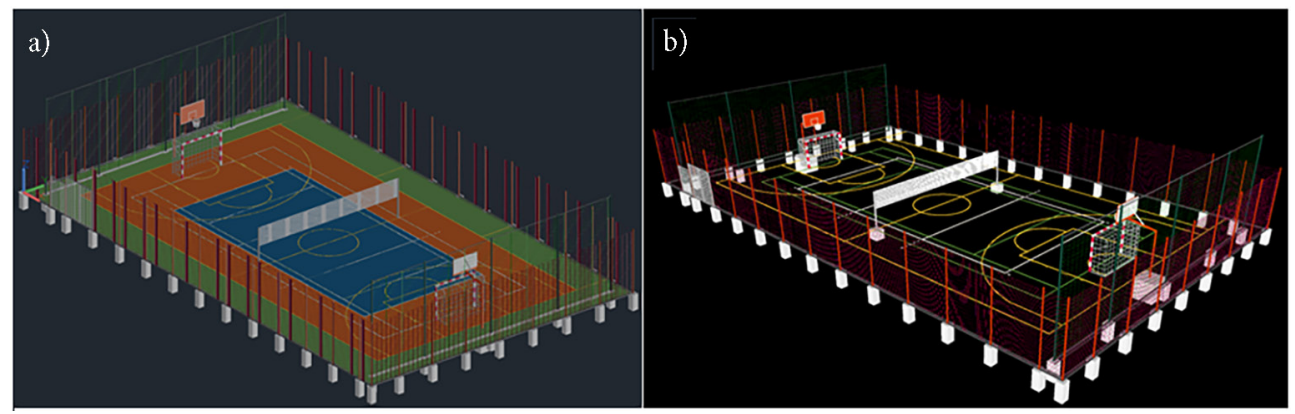

Figure 6. Sports field detailed BIM model: a) native format view, b) IFC format view

Table 10. Forecasts of the analysed sports field construction costs made with the use of four developed ensemble based models

\begin{tabular}{|c|c|c|c|c|c|c|c|c|c|c|c|}
\hline$p$ & $x_{1}$ & $x_{2}$ & $x_{3}$ & $x_{4}$ & $x_{5}$ & $x_{6}$ & $x_{7}$ & $\hat{y}_{E N S 1}$ & $\hat{y}_{\text {GEN2 }}$ & $\hat{y}_{\text {ENS3 }}$ & $\hat{y}_{\text {GEN4 }}$ \\
\hline 7 & 639.0 & 0.9 & 0.5 & 216.0 & 0.0 & 105.0 & 0.0 & 245.83 & 254.20 & 243.12 & 252.34 \\
\hline
\end{tabular}

vironment in terms of the air protection, water protection, greenery protection, soil protection, etc. Due to the results of ground and water conditions investigations, the ground conditions have been assessed as simple and the facility was qualified into the first geotechnical category. Basic parameters and information about the facility are given synthetically in Table 9.

For the analysed facility, a BIM model was developed by one of the authors of this research. Various BIM tools were used for the modelling purposes. A conceptual model of the sports field, visualisation of the object's location and surroundings as well as animations that complemented a visual presentation of the facility were prepared in the first step as presented in Figure 5. The BIM model was prepared in order to better present the location of the pitch in the field and elements of land development. The model is not part of the methodology of proceeding in the proprietary cost prediction model. However, it provides help in quickly calculating parameters characterising the object used in the calculations such as, for example, total area of the facility, playing field length, etc.

The model served as a source of information necessary in the course of cost analysis carried out with the use of the four developed regression models based on the ensembles of neural networks. The model was exported to the IFC format. With the use of an IFC viewer and plugins - that make possible the creation of advanced reports including ordered data extracted from the model - the authors prepared all the information, both quantitative and qualitative, necessary for the cost forecasts. The values of the $x_{j}$ variables were adopted on the basis of this information. Numerical values of the variables $x_{1}$ and $x_{4}-x_{7}$ have been read directly from the model. In the case of variables $x_{2}$ and $x_{3}$ categorical values read from the model have been pseudo fuzzy scaled according to the assumptions presented in Table 1. The values were used for predictions made by the four ensemble-based models - namely ENS 1, GEN 2, ENS 3 and GEN 4. Both input values and cost forecasts for the analysed sports field are presented in Table 10.
The actual cost, real life cost of construction works, in the case of the analysed sports field, amounted to 269.80 thousands of PLN. The errors of predictions provided by the four developed models are given in Table 11.

Table 11. Errors of predictions provided by the four developed ensemble based models

\begin{tabular}{|c|c|c|c|}
\hline Ensemble & $e=y-\hat{y}$ & $P E$ & $A P E$ \\
\hline ENS 1 & -23.97 & $-8.89 \%$ & $8.89 \%$ \\
\hline GEN 2 & -15.60 & $-5.78 \%$ & $5.78 \%$ \\
\hline ENS 3 & -26.68 & $-9.89 \%$ & $9.89 \%$ \\
\hline GEN 4 & -17.46 & $-6.47 \%$ & $6.47 \%$ \\
\hline
\end{tabular}

According to the errors presented in Table 11, in terms of the APE criteria all of the four forecasts errors are lower than $10 \%$, which makes the performance of the models satisfactory for the purpose of conceptual cost estimates. One can see that the straight calculations of errors $e$ are negative numbers in the case of all four models, and the values are relatively close, which makes the four predictions convergent. The best forecast, which was closest to the real life construction cost of the analysed sports field, was obtained for the GEN 2 model. The second best forecast was provided by the GEN 4 model. The GEN 2 and GEN 4 models gave better predictions than ENS 1 and ENS 3 by about $2-3 \%$ in terms of APE. The case study and the results of the analysis reveal the superiority of the ensembles based on generalised averaging for the conceptual cost estimate of a particular facility. The detailed model has been shown in order to present the possibilities offered by the BIM technology as well as show the further course of action after making the decision to continue the investment.

The detailed model was built in the next step and then checked and verified in terms of correctness, potential clashes and problems. Figure 6 presents alternative views of the detailed model. 


\section{Conclusions}

The research resulted in development of four original predictive models, based on neural networks ensembles, capable of forecasting the construction costs of sports fields. The variables of the models, their nature and values related to the features of sports fields as specific facilities and their construction costs. Ensembles were formed as a linear combination of individual multilayer perceptron neural networks. Two of the ensembles, namely ENS 1 and GEN 2 , were formed by the combination of networks varying in their architecture and activation functions, and two other ensembles, namely ENS 3 and GEN 4, were formed with the networks of the same architecture and activation functions. The authors employed two alternative approaches for the purposes of adoption of the weights assigned to the individual networks belonging to the ensembles - namely simple averaging in the case of the ENS 1 and ENS 3 ensembles, where the weights were assumed to be equal for the member networks, and generalised averaging in the case of the GEN 2 and GEN 4 ensembles (where the weights were computed as a result of an optimisation task for the member networks). According to the analysis and discussion, all of the four developed models proved good performance of cost prediction in the light of expectations applicable for conceptual estimates. Moreover, a general assessment of the four ensemble-based models revealed their superiority over the models based on single neural networks acting in isolation. MAPE errors computed after models testing was low, and varied between $2.73 \%$ and $3.91 \%$. The results were also satisfactory in terms of testing - all $A P E^{p}$ prediction errors for testing cases were lower than $10 \%$. The deviations of the predictions from the real life constructions costs are acceptable. A limitation of the proposed approach at the current stage of research is that the predictions offered by the developed ensemblebased models are made for the cost values updated for a certain year. In further research, this nuance is going to be investigated with a special attention.

To verify the predictive performance of the models, the authors also presented a case study including cost analysis based on the BIM model of a certain sports field. The process of cost analysis benefitted from the availability of the BIM model in terms of quick extraction of information and data necessary as input for the developed predictive models. The results of the BIM-based cost analysis for the particular sports field confirmed the capabilities of the four developed models - APE errors were smaller than $10 \%$. The obtained predictions were convergent and deviation of errors was small. The best prediction for the case study was given by the GEN 2 ensemble.

Although the quality of all of the four developed models is good and their performance is comparable, analysis of the testing results, as well as the findings resulting from the case study, enable selection of the GEN 2 ensemble as the best one.

The expectations and anticipations formulated at the beginning of the research have been confirmed. Specifi- cally, ensemble-based models allowed for balancing the strengths and weaknesses of member neural networks. Moreover, the combining of neural networks and forming ensembles allowed for compensation of prediction errors when compared to single neural networks acting in isolation. The effort put into training and verifying the number of neural networks has not been wasted. Necessary additional computations that arose from the ensemble-based approach take only a little more time than in the case of single network selection to be the core of the model. Forming ensembles based on a generalised averaging approach requires some more computations and optimisation than in case of simple averaging, however both approaches are relatively easy in their implementation. The approach proposed in this research is prospective for fast cost analyses and conceptual estimates of construction costs, and contributes in the studies on applications of neural networks and artificial intelligence in cost analyses in the construction industry.

\section{Funding}

This work was funded by statutory activities of Cracow University of Technology.

\section{Author contributions}

M. Juszczyk developed a concept of this research. M. Juszczyk and K. Zima made a review of the literature. K. Zima collected and ordered the data used later on in the modelling process. M. Juszczyk formulated assumptions, carried out modelling, developed neural models and obtained results. M. Juszczyk and K. Zima discussed the results. W. Lelek developed BIM model of a sports field presented in this work. K. Zima prepared the case study. M. Juszczyk and K. Zima together discussed and commented on the case study and formulated final conclusions.

\section{Disclosure statement}

All authors declare that they do not have any competing financial, professional, or personal interests from other parties.

\section{References}

Azhar, S. (2011). Building Information Modeling (BIM): Trends, benefits, risks, and challenges for the AEC industry. Leadership and Management in Engineering, 11(3), 241-252. https://doi.org/10.1061/(ASCE)LM.1943-5630.0000127

Bishop, C. M. (1995). Neural networks for pattern recognition. Clarendon Press. https://doi.org/10.1201/9781420050646.ptb6

Bryde, D., Broquetas, M., \& Volm, J. M. (2013). The project benefits of Building Information Modelling (BIM). International Journal of Project Management, 31(7), 971-980. https://doi.org/10.1016/J.IJPROMAN.2012.12.001

Cheng, M.-Y., Tsai, H.-C., \& Sudjono, E. (2012). Evolutionary fuzzy hybrid neural network for dynamic project success as- 
sessment in construction industry. Automation in Construction, 21, 46-51. https://doi.org/10.1016/J.AUTCON.2011.05.011

Cheung, F. K. T., Rihan, J., Tah, J., Duce, D., \& Kurul, E. (2012). Early stage multi-level cost estimation for schematic BIM models. Automation in Construction, 27, 67-77. https://doi.org/10.1016/J.AUTCON.2012.05.008

Dikmen, S. U., \& Sonmez, M. (2011). An artificial neural networks model for the estimation of formwork labour. Journal of Civil Engineering and Management, 17(3), 340-347. https://doi.org/10.3846/13923730.2011.594154

Eastman, C. M., Teicholz, P., Sacks, R., \& Liston, K. (2011). BIM handbook: a guide to building information modeling for owners, managers, designers, engineers and contractors. New York: John Wiley \& Sons.

El-Sawalhi, N. I., \& Shehatto, O. (2014). A neural network model for building construction projects cost estimating. Journal of Construction Engineering and Project Management, 4(4), 9-16. https://doi.org/10.6106/JCEPM.2014.4.4.009

Forgues, D., Iordanova, I., Valdivesio, F., \& Staub-French, S. (2012). Rethinking the cost estimating process through 5D BIM: A case study. In Construction Research Congress 2012 (pp. 778-786). Reston, VA: American Society of Civil Engineers. https://doi.org/10.1061/9780784412329.079

Grzyl, B., Miszewska-Urbańska, E., \& Apollo, M. (2017). Building information modelling as an opportunity and risk for stakeholders involved in construction investment process. Procedia Engineering, 196, 1026-1033. https://doi.org/10.1016/J.PROENG.2017.08.045

Guo, Z., Chen, Q., Wu, G., Xu, Y., Shibasaki, R., \& Shao, X. (2017). Village building identification based on ensemble convolutional neural networks. Sensors, 17(11), 2487. https://doi.org/10.3390/s17112487

Hakim, S., Razak, H. A., \& Ravanfar, S. (2016). Ensemble neural networks for structural damage identification using modal data. International Journal of Damage Mechanics, 25(3), 400430. https://doi.org/10.1177/1056789515598639

Hardin, B., \& McCool, D. (2015). BIM and construction management : proven tools, methods, and workflows. New York: John Wiley \& Sons.

Hashem, S., \& Schmeiser, B. (1995). Improving model accuracy using optimal linear combinations of trained neural networks. IEEE Transactions on Neural Networks, 6(3), 792-794. https://doi.org/10.1109/72.377990

Haykin, S. S. (1999). Neural networks: a comprehensive foundation. Prentice Hall.

Jovanović, R., Jovanović, R. Ž., \& Sretenović, A. A. (2017). Ensemble of radial basis neural networks with K-means clustering for heating energy consumption prediction. FME Transactions, 45, 51-57.

Juszczyk, M. (2017a). Studies on the ANN implementation in the macro BIM cost analyzes. Scientific Review Engineering and Environmental Sciences, 26(2), 183-192. https://doi.org/10.22630/PNIKS.2017.26.2.16

Juszczyk, M. (2017b). The challenges of nonparametric cost estimation of construction works with the use of artificial intelligence tools. Procedia Engineering, 196, 415-422. https://doi.org/10.1016/j.proeng.2017.07.218

Juszczyk, M., Leśniak, A., \& Zima, K. (2018). ANN based approach for estimation of construction costs of sports fields. Complexity, Article ID 7952434. https://doi.org/10.1155/2018/7952434
Juszczyk, M., \& Zima, K. (2018). Clustering of sports fields as specific construction objects aided by Kohonen's neural networks. AIP Conference Proceedings, 1978, 240009. https://doi.org/10.1063/1.5043870

Kalibatas, D., Kalibatienè, D., \& Kapliński, O. (2018). A systematic review of information modelling of individual residential Buildings. Engineering Structures and Technologies, 10(2), 5871. https://doi.org/10.3846/est.2018.6479

Leśniak, A., \& Juszczyk, M. (2018). Prediction of site overhead costs with the use of artificial neural network based model. Archives of Civil and Mechanical Engineering, 18(3), 973-982. https://doi.org/10.1016/j.acme.2018.01.014

Leśniak, A., \& Zima, K. (2018). Cost calculation of construction projects including sustainability factors using the Case Based Reasoning (CBR) method. Sustainability, 10(5), 1608. https://doi.org/10.3390/su10051608

Liu, M., \& Ling, Y. Y. (2005). Modeling a contractor's markup estimation. Journal of Construction Engineering and Management, 131(4), 391-399.

https://doi.org/10.1061/(ASCE)0733-9364(2005)131:4(391)

Mrówczyńska, M. (2011). Neural networks and neuro-fuzzy systems applied to the analysis of selected problems of geodesy. Computer Assisted Mechanics and Engineering Sciences, 18(3), 161-173.

Naik, M. G., \& Kumar, D. R. (2015). Construction project cost and duration optimization using artificial neural network. In AEI 2015 (pp. 433-444). Reston, VA: American Society of Civil Engineers. https://doi.org/10.1061/9780784479070.038

Osowski, S. (1997). Sieci neuronowe w ujęciu algorytmicznym. Wydawnictwa Naukowo-Techniczne.

Park, T., Kang, T., Lee, Y., \& Seo, K. (2014). Project cost estimation of national road in preliminary feasibility stage using BIM/GIS platform. In Fifth International Conference "Computing in Civil and Building Engineering" (V-ICCCBE) (pp. 423-430). Reston, VA: American Society of Civil Engineers. https://doi.org/10.1061/9780784413616.053

Pavlovskis, M., Antucheviciene, J., \& Migilinskas, D. (2017). Assessment of buildings redevelopment possibilities using MCDM and BIM techniques. Procedia Engineering, 172, 846850. https://doi.org/10.1016/J.PROENG.2017.02.083

Petroutsatou, K., Georgopoulos, E., Lambropoulos, S., \& Pantouvakis, J. P. (2012). Early cost estimating of road tunnel construction using neural networks. Journal of Construction Engineering and Management, 138(6), 679-687. https://doi.org/10.1061/(ASCE)CO.1943-7862.0000479

Rashidi, A., Jazebi, F., \& Brilakis, I. (2011). Neurofuzzy genetic system for selection of construction project managers. Journal of Construction Engineering and Management, 137(1), 17-29. https://doi.org/10.1061/(ASCE)CO.1943-7862.0000200

Reizgevičius, M., Ustinovičius, L., Cibulskienè, D., Kutut, V., \& Nazarko, L. (2018). Promoting sustainability through investment in building information modeling (BIM) technologies: A design company perspective. Sustainability, 10(3), 600. https://doi.org/10.3390/su10030600

Schabowicz, K., \& Hoła, B. (2007). Mathematical-neural model for assessing productivity of earthmoving machinery. Journal of Civil Engineering and Management, 13(1), 47-54. https://doi.org/10.1080/13923730.2007.9636418

Sharkey, A. J. C. (1999). Combining artificial neural nets: ensemble and modular multi-net systems. Springer. https://doi.org/10.1007/978-1-4471-0793-4 
Skiba, M., Mrówczyńska, M., \& Bazan-Krzywoszańska, A. (2016). Modeling the economic dependence between town development policy and increasing energy effectiveness with neural networks. Case study: The town of Zielona Góra. Applied Energy, 188, 356-366. https://doi.org/10.1016/j.apenergy.2016.12.006

Tadeusiewicz, R. (1993). Sieci neuronowe. Akademicka Oficyna Wydawnicza.

Urzad Zamówień Publicznych. (2019). Retrieved from https://www.uzp.gov.pl/urzad-zamowien-publicznych

Ustinovichius, L., Popov, V., Cepurnaite, J., Vilutiene, T., Samofalov, M., \& Miedziałowski, C. (2018). BIM-based process management model for building design and refurbishment. Archives of Civil and Mechanical Engineering, 18(4), 1136-1149. https://doi.org/10.1016/J.ACME.2018.02.004

Yazdani-Chamzini, A., Zavadskas, E., Antucheviciene, J., \& Bausys, R. (2017). A model for shovel capital cost estimation, using a hybrid model of multivariate regression and neural networks. Symmetry, 9(12), 298.

https://doi.org/10.3390/sym9120298

Yip, H., Fan, H., \& Chiang, Y. (2014). Predicting the maintenance cost of construction equipment: Comparison between general regression neural network and Box-Jenkins time series models. Automation in Construction, 38, 30-38. https://doi.org/10.1016/J.AUTCON.2013.10.024

Zhao, Z., Gong, Q., Zhang, Y., \& Zhao, J. (2007). Prediction model of tunnel boring machine performance by ensemble neural networks. Geomechanics and Geoengineering, 2(2), 123-128. https://doi.org/10.1080/17486020701377140

Zima, K. (2015). The case-based reasoning model of cost estimation at the preliminary stage of a construction project. Procedia Engineering, 122, 57-64. https://doi.org/10.1016/j.proeng.2015.10.007

Zima, K. (2017). Impact of information included in the BIM on preparation of bill of quantities. Procedia Engineering, 208, 203-210. https://doi.org/10.1016/j.proeng.2017.11.039

\section{Notations}

Variables and functions

$x_{j}$ - independent variables, cost predictors selected for sports fields as specific construction objects;

$y$ - dependent variable, real life values of sports fields construction costs;

$\hat{y} \quad$ - predicted values of dependent variable $y$;

$h$ - regression function implemented by a single neural network;

$f_{k}$ - regression function implemented by $k$-th neural network selected to be a member of an ensemble.

\section{Abbreviations}

ANN - artificial neural network;

BIM - building information model / building information modelling;

ENS 1 - model based on simple ensemble averaging, consisting of various artificial neural networks;

ENS 3 - model based on simple ensemble averaging, consisting of artificial neural networks of the same type;

GEN 2 - model based on generalised ensemble averaging, consisting of various artificial neural networks;

GEN 4 - model based on generalised ensemble averaging, consisting of artificial neural networks of the same type;

MREG - model based on multiple regression;

MLP - multilayer perceptron;

RMSE - root mean squared error;

$M A P E$ - mean absolute percentage error;

$A P E^{p}$ - absolute percentage error for $p$-th sample. 